\title{
Euthanasia: A Challenge to Medical Ethics
}

\author{
Rui Nunes*and Guilhermina Rego \\ Centre of Bioethics, Faculty of Medicine of the University of Porto, Alameda Prof. Hernâni Monteiro, 4200-319, Porto, Portugal
}

*Corresponding author: Rui Nunes, Centre of Bioethics, Faculty of Medicine of the University of Porto, Alameda Prof. Hernâni Monteiro, 4200-319, Porto, Portugal, Tel: +351-225513625; Fax: +351 225513697; E-mail: ruinunes@med.up.pt

Received date: July 31, 2016; Accepted date: August 18, 2016; Published date: August 20, 2016

Copyright: ( 2016 Nunes R, et al. This is an open-access article distributed under the terms of the Creative Commons Attribution License, which permits unrestricted use, distribution, and reproduction in any medium, provided the original author and source are credited

\section{Introduction}

For many decades the euthanasia debate is particularly controversial in modern societies. Indeed, in the northern European tradition, as well as in countries of Anglo-American influence, euthanasia, physician-assisted suicide and other end-of-life decisions are an important source of social debate. It is well known that in many circumstances, medical decision-making often contributes to hasten the death of a particular patient and different societies have different understandings with regard to the specific role of health professionals in this setting. Moreover, death usually happens in the hospital, far away from family and friends, at an environment more prone to loneliness and abandonment. The rise of the hospice movement in the sixties and, more recently of palliative care as a new philosophical and practical approach to death and dying, is also a sign that this issue should be properly addressed as a major cultural transition. Indeed, as suggested by John Keown in his book Euthanasia, Ethics and Public Policy "whether the law should permit voluntary euthanasia or physician-assisted suicide is one of the most vital questions facing all modern societies" [1].

There have been many attempts to legalize euthanasia in the western world, but only a few have succeeded. There are plenty of good reasons why euthanasia should or should not be legalized. Traditionally, in most countries with a Christian tradition, euthanasia and physicianassisted suicide was a morally condemned practice due to the sanctity of human life. However, the emergence of secular pluralistic societies gave a different meaning to the concept of personal autonomy, and the right to self-determination is a progressively recognized value of modern societies. Both as a negative right as a positive one meaning that the "realization of an ideal of a more perfect humanity as conceived by reason" [2]. Therefore, western countries are not so prone in condemning voluntary euthanasia and physician-assisted suicide, and are now faced with contradictory political and social evidences with regards to these practices. Indeed, although there should exist a consensus over death and dying, conflict has come to dominate the debate [3].

However, from a strict medical ethics perspective, international guidelines following the Hippocratic Oath and the World Medical Association Declaration of Geneva still consider euthanasia and physician-assisted suicide as a morally forbidden practice. The objective of this paper is to determine what might be the consequences to medical ethics, in a global perspective, with the legalization of euthanasia in a growing number of countries. Specifically, how should the medical codes of ethics adapt to such an evolution in an ethical consistent way.

\section{Euthanasia and the Right to Choose}

Although there is a strong debate in modern societies over the legalisation of physician-assisted suicide, many ethicists of different philosophical backgrounds are comfortable with voluntary euthanasia and the right to die with dignity [4]. For instance, it is well known that libertarians, such as Tristram Engelhardt Jr., contend that there is no ethical difference between killing and letting dye as long as the mutual consent of involved parties is obtained [5]. Also, from a utilitarian perspective, James Rachels in his book "The Elements of Moral Philosophy" [6] suggested that "euthanasia may be morally right" and that "the argument can be summarized as this:

a) "The morally right thing to do, on any occasion, is whatever would bring about the greatest balance of happiness over unhappiness;

b) On at least some occasions, the greatest balance of happiness over unhappiness may be brought about by mercy killing;

c) Therefore, on at least some occasions, mercy killing may be morally right".

This evolution happened primarily in northern Europe and in countries of Anglo-American tradition. However, even in southern European countries, as well as in countries that share common traditions and cultural backgrounds, such as Latin America countries, there is evidence available that shows a similar evolution regarding the practice of euthanasia. Although in Mediterranean countries there is a longstanding tradition of respecting the sanctity of human life, legalisation of assisted death is now also in the political agenda. Indeed, in the last decades the sociological background of many southern European countries has changed dramatically, namely due to an increase in life expectancy, a decreased influence of the Roman Catholic Church, as well as a different role of the family as an informal carer. The nuclear family is smaller, with a substantial decrease of the birth rate and, consequently, there are fewer members to take care of the older family members, especially with chronic and terminal conditions.

In this changing social and cultural settings, it is expected that new approaches regarding assisted death are steadily developed all over the civilized world, as many people, namely terminal patients, have frequent thoughts about death and dying and believe that the practice of euthanasia should be considered as an acceptable public policy. Also, and from an ethical perspective, it is well known that some terminal patients feel that physician-assisted suicide and euthanasia can be a valid option at the end of life and that this practice is within the limits of the right to self-determination. Amongst the various motives for requesting assisted death, it is of significance the fact that the person feels alone and has difficulty in self-care. The reasons why a terminal patient has this opinion are, in general, related to feelings of abandonment leading to a collapse of the individual's life project. Indeed, the inexistence of clear objectives to self-fulfilment may be 
related to thoughts about dying, leading to the assumption that the individual's life project might be perceived as already accomplished [7].

Also, many patients that request physician-assisted suicide claim that their reasons are the loss of autonomy and dignity and also the incapacity to engage in activities that give their life meaning. For instance, the Dutch law on euthanasia refers to "unbearable suffering" as the criterion to request euthanasia. That is, this law refers to a subjective evaluation by the patient, not presenting any feasible alternatives to a death with dignity. However "unbearable suffering" is not a technical term but a subjective personal condition that will determine the choice for a merciful death [8].

Also, it is clear that euthanasia is conceptually different from other issues such as withholding and withdrawing life-prolonging medical treatment in terminal patients, namely futile and heroic treatments, sedation for refractory symptoms of terminal patients that may hasten death, or even decisions to forego medical treatment in the persistent vegetative status [9]. The alleviation of severe symptoms sometimes involves the use of drugs that may be life shortening as a potential side effect. But, it is beyond the scope of this paper to evaluate the ethics of withholding or withdrawing of medical treatment [10], namely because in general they are an accepted medical practice. And, therefore no specific changes are needed in most codes of medical ethics.

Different variables can influence a specific request of euthanasia that is the practice of administrating, supplying or prescribing drugs with the explicit intention of hastening death, resulting in the patient's death. If it is true that some of these variables are difficult to overcomesuch as death or absence of family members-other variables can and should be dealt with before a policy of physician-assisted suicide is implemented and legalised-for instance, a nationwide program of palliative care. Euthanasia can only be considered an ethical option if is it an expression of the person's autonomy. It is argued that any undue influence in the patient's will-such as a treatable depressionundermines the concept of voluntary euthanasia. Also, it is unacceptable that any request of euthanasia is grounded on unbearable pain because nowadays most healthcare systems should provide adequate pain management services. In any case, unbearable suffering should never be equivalent to unbearable pain and physicians should be particularly acquainted with this difference.

Furthermore, it is frequently wondered if a terminally ill patient with unbearable suffering finds acceptable to ask a physician to terminate his or her life. That is, if voluntary euthanasia and/or physician-assisted suicide should be legalized and incorporated in medical practice. Indeed, there is a difference between the moral acceptance of a practice and its legalisation. Legalisation implies a social shift in fundamental values because any law has a specific set of ethical principles in its internal framework. Indeed, the public opinion of many democratic countries is favourable to the legalisation of voluntary euthanasia. A recent survey by the Institute DEXUS in Spain pointed out that $79 \%$ of the Spanish population accepted physicianassisted death. Namely, the changing family patterns-with a different role of the woman both in the family and in the labour force, fewer children per couple, the increased professional mobility, etc. inevitably leads to a decrease of the significance of informal caring of patients at the end of life, namely in large urban areas.

This trend is probably related as well to the international discussion over voluntary euthanasia. However, the unethical consequences of legalising voluntary euthanasia, such as involuntary or non-voluntary euthanasia, are an important argument to be ruled out. A thorough analysis of the empirical evidence gathered from Oregon (were physician-assisted suicide is legalised through the Oregon Death with Dignity Act), the Australian Northern Territory (where euthanasia and physician-assisted suicide were temporarily legalised through the Rights of the Terminally Ill Act of 1995), and also the Dutch and Belgic experience, seems to be paramount [11]. In the Netherlands, the first country to legalise euthanasia, Heide et al. demonstrated that, in 2005 , $1,7 \%$ of all deaths were the result of euthanasia [12]. Also, in Belgium it is estimated that about 30 percent of all deaths are preceded by palliative care and that about 2 percent are through euthanasia [13].

In other countries, the debate over euthanasia is just beginning and issues such as death with dignity will lead necessarily to a balance between autonomy of the patient and his or her best interests from a societal perspective [14]. Nevertheless, the debate will be more fruitful if on one hand the access to palliative care becomes universal and on the other hand there is an adequate training of healthcare professionals in end-of-life decision-making [15]. In the long run, however, physician-assisted death will be much more accepted if the fears of involuntary and non-voluntary euthanasia are ruled out. Also, common conditions such as depression and anxiety should be detected. But, as Ganzini et al. demonstrated in a cross sectional survey performed with patients requesting physician's aid in dying in Oregon, most patients who requested physician assistance in dying did not have a depressive disorder [16]. The prevalence of depression and anxiety should nonetheless be monitored so that society is reassured of the autonomous nature of euthanasia.

Evaluating the rights of vulnerable populations-especially those that are unable to decide for themselves-should be a milestone in the debate over the public policy on euthanasia. The distinction between voluntary and involuntary euthanasia seems paramount from an ethical and even a legal perspective. And, medical ethics must also address this issue properly namely in the professional setting.

\section{Medical Ethics in a Global Perspective}

Some developed countries and societies that share the same traditions and ideals have a longstanding practice of publicly discussing euthanasia and physician-assisted suicide, sometimes empowering the society to directly deliberate over these issues. However, in other countries euthanasia was considered as a proscribed practice because of the intrinsic disvalue of killing humans. Also, from a hypocratical perspective, euthanasia is always wrong because the fiduciary nature of the patient/physician relation would be at stake if the patient did not completely trust his or her physician [17]. That is, euthanasia and physician-assisted suicide usually weren't considered as an option and personal autonomy was limited namely regarding death and dying. Traditionally, the objectives of medicine were to cure, to care and to alleviate the patient's suffering [18]. The internal morality of medicine would be questioned if its fundamental goals were changed in a way not compatible with the protection of human dignity, such as putting an end to the patient's life [19]. Moreover, professional autonomy acknowledges the right to conscientious objection and therefore medical ethics recognises the right of a particular physician to reject the practice of euthanasia, even if this practice is in accordance with the law [20]. Physicians' religious or moral values are usually considered as a valuable reason to object certain practices, such as euthanasia or assisted suicide.

For instance, the International Code of Medical Ethics of the World Medical Association [21] states that "A physician shall always bear in 
Page 3 of 5

mind the obligation to respect human life" and the Medical Ethics Manual of the World Medical Association states that "Euthanasia, that is the act of deliberately ending the life of a patient, even at the patient's own request or at the request of close relatives, is unethical. This does not prevent the physician from respecting the desire of a patient to allow the natural process of death to follow its course in the terminal phase of sickness" [22]. Indeed, and in accordance with Peter Hudson, it might be asked "Who would be the individuals or groups of healthcare professionals charged with the responsibility for enabling and enacting EAS (euthanasia and assisted suicide)? What training, supervision, scrutiny, and reporting of effective practice would be required for those teaching medical, nursing, and allied health students? How would this affect the training of clinicians in the care of seriously ill patients when it is already acknowledged that current health professionals' training does not adequately equip them for these roles?" [8]. Also, the consequences to the internal morality of medicine of such an evolution should be evaluated, namely in the professional evolution of physicians and in the construction of his or her moral character [23].

Although this traditional and historic context, even within the medical profession, there is a progressive acceptance of euthanasia and physician-assisted suicide, namely in intensive care, oncology or even palliative care. A study carried out by Lindblad et al. concludes that there is no clear majority among Swedish physicians for or against physician-assisted suicide and that significantly more senior physicians accept this practice [24]. Even at the Unites States, the medical community is not unanimous regarding physician-assisted suicide. A 2003 study of AMA members showed that only $69 \%$ objected to physician-assisted suicide [25], meaning that more than $30 \%$ of the inquired physicians did not have such strong convictions about this issue.

In short, there are valuable arguments for and against the practice of voluntary euthanasia that are synthesised by Margaret Battin, as follows [26]:

a) For: respect for personal autonomy, relief of the pain and unbearable suffering, and quality of life;

b) Against: intrinsic wrongness of killing, integrity of the profession, and potential abuse (slippery slope).

The debate over the legalisation of euthanasia and physician-assisted suicide often warned of a "slippery slope", predicting abuse of people in vulnerable groups, namely children. Indeed, some of the worst fears of legalising euthanasia and physician-assisted death will still remain because, as stated by John Keown, it will always be difficult to implement strong mechanisms of supervision and control with the potential for abuse of vulnerable populations. This author claims that in the United Kingdom the Lord Joffe's Assisted Dying for the Terminally Ill Bill of 2006 was rejected by 148 votes against 100 because a set of regulatory recommendations to prevent abuse were not considered in its proposal [27].

However, Battin et al. showed that there is no evidence whatsoever of a heightened risk of involuntary euthanasia of the elderly, women, the uninsured, people with low educational status, the poor, or the physically disabled in Oregon or the Netherlands [28]. Many authors stand for a regulatory policy where assisted death is effectively monitored by authorized officials. In this way, the prevention of nonvoluntarily and involuntary euthanasia would be more easily accomplished [29]. Indeed, for a valid consent, and in accordance for instance with Beauchamp and Childress, the consent should be completely voluntary: "a person acts voluntarily to the degree that he or she wills the action without being under the control of another's influence. We considered here only control by other individuals, although conditions such as debilitating disease, psychiatric disorders, and drug addiction can also diminish or void voluntariness" [18]. For a valid "individual" consent of the child (presuming an already acquired competency to decide), parental consent is not necessary, as it is eventually disruptive of a true voluntary consent [5].

To further implement effective supervision, it has been suggested that medical training should emphasise learning skills to deal with death and the dying process, especially primary care physicians that should be able to determine if the person who asks for euthanasia does not want to live in those circumstances or does not want to live at all [30]. Also, the psychological impact associated to the practice of euthanasia or assisted suicide and to the loss of a close person through assisted suicide should be evaluated. Preliminary results in a Swiss study suggest that a higher prevalence of Post-Traumatic Distress Disorder and depression is found in relatives that witnessed those practices in Switzerland, but the prevalence of complicated grief is comparable to that reported by the general Swiss population [31].

From a medical perspective, and although euthanasia is prohibited by traditional medical ethics, physicians are more prone to engage in practices that deliberately hasten death if the patient is in end-stage disease with unbearable suffering (regarded as unrelieved and intractable suffering) whether by reasons of pain, distress or otherwise by which the patient finds so severe as to be an unacceptable condition. In specific cases, it is not only considered an acceptable medical practice but it is even integrated with palliative care as a true Eueuthanasia [32]. It has been suggested that the creation of a centrally run system would remove the physician's direct involvement in euthanasia or assisted suicide. Prokopetz and Lehmann [33] envision "the development of a central state or federal mechanism to confirm the authenticity and eligibility of patients' requests, dispense medication, and monitor demand and use. Such a mechanism would obviate physician involvement beyond usual care". This is close to the Swiss model, according to which volunteers assist suicide of consenting persons, and not physicians. However, the ethical foundation of this proposal is not clear because it could be argued that if euthanasia or physician-assisted suicide is legal, so consenting physicians should not be deprived of engaging in a practice that is in accordance with his or her conscience.

In a global perspective, there are countries (or states) where euthanasia or physician-assisted suicide is accepted and legalised and others where it is still a criminal offence. To preserve the integrity of medicine, it is suggested in this paper that codes of ethics both in individual countries as well as at an international level become neutral with regard to euthanasia or physician-assisted suicide. It means that international organisations that regulate medical practice at a worldwide level should promote a change in their codes of ethics, perhaps incorporating a general expression such as "A physician shall always bear in mind the obligation to promote death with dignity" being "death with dignity" a concept subjectively interpreted by any physician in accordance with his or her ethical beliefs.

It follows that, from an international medical ethics perspective, euthanasia and physician-assisted suicide should be dealt at a professional and personal conscience level and, eventually, a conscientious objection due to the fact that it is no longer arguable (at least in some cultural settings) that "Euthanasia, that is the act of deliberately ending the life of a patient, even at the patient's own 
request or at the request of close relatives, is unethical" [22]. Indeed, in societies that have legalised euthanasia and physician-assisted suicide, many physicians have accepted and deliver these practices, and likewise the majority of their peers are ethically in accordance that this is a true medical act.

Thus, for the patient/physician relationship to remain a fiduciary one all over the world, and considering also the high mobility that people have due to the cultural and economic globalisation (both patients and physicians), international codes of ethics should evolve, as well as national one's, namely in Europe and other geopolitical communities. For instance, the American Medical Association, although considering that "permitting physicians to engage in euthanasia would ultimately cause more harm than good", actively suggests that "Preserving opportunity for physicians to act (or to refrain from acting) in accordance with the dictates of conscience in their professional practice is important for preserving the integrity of the medical profession as well as the integrity of the individual physician, on which patients and the public rely. Thus physicians should have considerable latitude to practice in accord with wellconsidered, deeply held beliefs that are central to their self-identities." [34].

This proposal is not only based in common sense, but it is likely to maintain a global ethical unity in medicine worldwide, because it would still be the same ethics and the same international (or national) code, although with different interpretations and approaches. We believe this solution is considerably better for medical ethics than allowing for a variable geometry in this field, according to which every national medical organization determines its own ethical rules and guidelines.

\section{Conclusion}

Physician-assisted death is one of the most stringent debates of modern societies. Although different countries have particular social and religious backgrounds, most developed societies are progressively engaging in such debate. The rapid change of the sociological environment all over the world anticipates that the legalisation of voluntary euthanasia will take place in more countries in the near future. As Quill suggests, there are several things that should previously be cleared before legalising euthanasia and physicianassisted suicide [35]. First of all, palliative care is the standard of assistance for addressing the suffering of seriously ill patients [36]. This follows that public policies should address the issue of improving the access and delivery of palliative care [37]. Secondly, and despite of state-of-the-art of palliative measures, there will always remain some patients whose suffering is insufficiently relieved. Several "last resort" options could address many of these cases [38]. Aggressive pain management, forgoing life-sustaining therapies and sedation to unconsciousness are a common practice to relieve suffering, even if death is hastened.

Also, self-determination at the end of life should be promoted. For example, legalising the living will to allow an easier withdrawal or withholding of futile treatments gives a sense of control that is usually felt as an opportunity to alleviate pain and suffering. In this vein, Tolle et al. have suggested that the availability of such an escape, as euthanasia, may be much more important to many individuals than its actual use [39]. Moreover, evidence shows that the legalisation of euthanasia and physician-assisted suicide enhances rather than undermines other aspects of palliative and end-of-life care. For instance, according to Jan Bernheim "In what has become known as the Belgian model of integral end-of-life care, euthanasia is an available option, also at the end of a palliative care pathway. This approach became the majority's view among the wider Belgian public, palliative care workers, other health professionals and legislators. The legal regulation of euthanasia in 2002 was preceded and followed by a considerable expansion of palliative care services" [13].

In this global context, medical ethics should have the insight to evolve accordingly and to promote true universal values in death and dying. If some practices are universally considered as consensual one's - such as withholding or withdrawing futile treatments, the living will or even palliative sedation-euthanasia and physician-assisted suicide are ethically disruptive, even from the medical ethics point of view. Only by letting physicians abide to their conscience will medical ethics be allowed to remain universally unquestioned.

Indeed, the goal is not to reach the lowest common denominator but only to allow some responsiveness of medical ethics, so it can adapt to specific cultural settings. Of course there are some values that are indisputable, such as respect for personal autonomy, medical integrity, or protection of vulnerable people and populations. But ethics in medicine cannot stay completely static because social values evolve steadily by themselves. Probably the best strategy will be to resort to some kind of "glocalisation" of medical ethics so that consensual universal principles do not contend with particular ethical views of medical practice.

In the absence of such strategy, and if the actual global code of medical ethics is ignored in some countries and cultures, medical ethics might be severely undermined in the near future. This new role for a global ethics is dependent of the existence of practical ways to implement and to divulge these universal ethical principles. And it also implies a fair way to determine the consensus. Tristram Engelhardt Jr. speaks of reaching a consensus in ethics by mutual consent [5]. It follows that in a medical ethics perspective public deliberation, meaning medical deliberation, could be a solution. This kind of method is particularly appealing when there are apparently irreconcilable moral perspectives-for instance with regard to euthanasia-nevertheless, there is a common will to reach a consensus [40]. By consensus it is meant not the consensual resolution of a particular ethical dilemma but a consensus regarding the way physicians should individually deliberate and decide. Consensus also implies some degree of compromise between different views of a good life.

\section{References}

1. Keown J (2002) Euthanasia, ethics and public policy. An argument against legalisation. Cambridge: Cambridge University Press.

2. Jennings B (2016) Reconceptualizing autonomy: A relational turn in bioethics. Hastings Cent Rep 46: 11-16.

3. Dubler N (2005) Conflict and consensus at the end life. Hastings Cent Rep 35: 19-25.

4. Harris J (1991) The value of life. An introduction to medical ethics. Routledge, London.

5. Engelhardt T (1996) The foundations of bioethics (2nd edn.) Oxford University Press, New York.

6. Rachels J (2007) The elements of moral philosophy (5th edn.) McGrawHill College, New York.

7. Johnson S (2005) Making room for dying: End of life care in nursing homes. Hastings Cent Rep 35: 37-41. 
Page 5 of 5

8. Hudson P, Hudson R, Philip J, Boughey M, Kelly B, et al. (2015) Legalizing physician-assisted suicide and/or euthanasia: Pragmatic implications. Palliat Support Care 13: 1399-1409.

9. Claessens P, Menten J, Schotsmans P, Broeckaert B (2008) Palliative sedation: A review of the research literature. J Pain Symptom Manage 36: 310-333.

10. Stanley J (1989) The Appleton Consensus: Suggested international guidelines for decisions to forego medical treatment. J Med Ethics 15 129-136.

11. Stoffell B (1998) Voluntary euthanasia, suicide and physician-assisted suicide. In: A companion to bioethics (edn.) Kuhse H, Singer P, Oxford: Blackwell Publishers Ltd, 272-279.

12. Van der Heide A, Onwuteaka-Philipsen BD, Rurup ML, et al. (2007) Endof-life practices in The Netherlands under the euthanasia act. N Engl J Med 356: 1957-1965.

13. Bernheim JL, Distelmans W, Mullie A, Ashby MA (2014) Questions and answers on the Belgian model of integral end-of-life care: Experiment? Prototype? "Eu-Euthanasia": The close historical, and evidently synergistic, relationship between palliative care and euthanasia in Belgium: An interview with a doctor involved in the early development of both and two of his successors. J Bioeth Inq 11: 507-529.

14. Dresser R (2005) Schiavo's legacy: The need for an objective standard. Hastings Cent Rep 35: 20-22.

15. Callahan D (2005) Death: "The distinguished thing”. Hastings Cent Rep 35: 5-8.

16. Ganzini L, Goy E, Dobscha S (2008) Prevalence of depression and anxiety in patients requesting physician's aid in dying: Cross sectional survey. BMJ 337: 1-5.

17. Pellegrino E (1992) Doctors must not kill. J Clin Ethics 3: 95-102.

18. Beauchamp T, Childress J (2013) Principles of biomedical ethics (7th edn.) Oxford University Press, New York.

19. Loewy E (1992) Healing and killing, harming and not harming: Physician participation in euthanasia and capital punishment. J Clin Ethics 3: 29-34.

20. Savulescu J (2006) Conscientious objection in medicine. BMJ 332: 294-297.

21. World Medical Association (2006) International code of medical ethics Adopted by the 57th WMA General Assembly, Pilanesberg, South Africa.

22. World Medical Association (2015) Medical Ethics Manual. In: Williams JR, (3rd Edn.), Ferney-Voltaire.

23. Boudreau J (2011) Physician-assisted suicide and euthanasia: Can you even imagine teaching medical students how to end their patients' lives? Perm J 15: 79-84.

24. Lindblad A, Löfmark R, Lynöe N (2008) Physician-assisted suicide: A survey of attitudes among Swedish physicians. Scand J Public Health 36 720-727.
25. Curlin FA, Nwodim C, Vance JL, Chin MH, Lantos JD (2008) To die, to sleep: US physicians' religious and other objections to physician assisted suicide, terminal sedation, and withdrawal of life support. Am J Hosp Palliat Care 25: 112-20.

26. Battin M (2003) Euthanasia and physician-assisted suicide. In: The Oxford handbook of practical ethics, LaFollette $\mathrm{H}$ (edn.), Oxford: Oxford University Press.

27. Keown J (2007) Physician-assisted suicide: Lord Joffe's slippery bill. Med Law Rev 15: 126-135.

28. Battin M, Van der Heide A, Ganzini L, et al. (2007) Legal physicianassisted dying in Oregon and the Netherlands: Evidence concerning the impact on patients in "vulnerable" groups. J Med Ethics 33: 591-597.

29. Quill T (2007) Physician-assisted death in vulnerable populations. BMJ 335: 625-626.

30. Van Marwijk H, Ilinka H, Van Royen P, The AM (2007) Impact of euthanasia on primary care physicians in The Netherlands. Palliat Med 21: 609-614.

31. Wagner B, Muller J, Maercker A (2012) Death by request in Switzerland: Posttraumatic stress disorder and complicated grief after witnessing assisted suicide. Euro Psychiatry 27: 542-546.

32. Berghe V, Mullie PA, Desmet M, Huysmans G (2013) Assisted dying The current situation in Flanders: Euthanasia embedded in palliative care. Euro J Palliat Care 20: 266-272.

33. Prokopetz J, Lehmann L (2012) Redefining physicians' role in assisted dying. N Engl J Med 367: 97-99.

34. Code of Medical Ethics (2015) Council on Ethical and Judicial Affairs, American Medical Association 2014-2015.

35. Quill T (2008) Physician-assisted death in the United States: Are the existing "last resorts" enough. Hastings Cent Rep 38: 17-22.

36. Foley K (2005) The past and the future of palliative care. Hastings Cent Rep 35: 42-46.

37. Holman J, Brendel D (2006) The ethics of palliative care in psychiatry. J Clin Ethics 17: 333-338.

38. Steinbrook R (2008) Physician-assisted death - From Oregon to Washington State. N Engl J Med 359: 2513-2515.

39. Tolle S, Tilden V, Drach L, Fromme E, et al (2004) Characteristics and proportion of dying Oregonians who personally consider physicianassisted suicide. J Clin Ethics 15: 111-118.

40. Solomon S, Abelson A (2012) Why and when should we use public deliberation. Hastings Cent Rep 42: 27-29. 